\title{
COMPUTER GUIDED ALGORITHM FOR SEGMENTAL MANDIBULAR RESECTION AND TITANIUM PLATE RECONSTRUCTION
}

\author{
Niveen Askar* and Sherif $\mathrm{Ali}^{* *}$
}

\begin{abstract}
Aim: The aim of this study was to introduce and assess a new computer guided algorithm using locating holes and cutting guides, for mandibular segmental resection in cases with massive contour deformity.

Patients and Methods: This was a prospective study conducted on 6 consecutive cases with mandibular odontogenic neoplasms indicating lateral segmental mandibular resection. For all the patients, computer guided resection and titanium plate reconstruction using locating holes and cutting guides was performed. The patients were followed up for 6 months; and recurrence, appearance, occlusion, maximum incisal opening (MIO), midline shift, chewing, swallowing, speech, pain were recorded.
\end{abstract}

Results: No recurrence occurred in the study till the end of follow up period. $33.3 \%$ of the observed minor change in appearance, and $66.7 \%$ observed no appearance change. No major disruption in occlusion occurred for any patient. The mean MIO was $41.8 \pm 4.35 \mathrm{~mm}$ after $1 \mathrm{month}$, $42.3 \pm 3.98 \mathrm{~mm}$ after 6 months, with no statistically significant difference. Chewing, swallowing, and speech were as normal for 5 patients $(83.3 \%)$.

Conclusions: The computer guided resection and titanium plate reconstruction using locating holes and cutting guides was found to be beneficial with promising results regarding function and aesthetics, we recommend the use of this technique for initial resection and reconstruction in delayed grafting. Yet, its use as a definitive reconstruction should be subjected to longer follow up period studies.

KEYWORDS: Computer assisted surgery, Mandibular resection, Mandibular reconstruction, Titanium reconstruction plate

* Associate Professor at Department of Oral \& Maxillofacial Surgery, Faculty of Dentistry, Cairo University, Egypt

** Lecturer at the Department of Oral and Maxillofacial Surgery. Faculty of Dentistry, Cairo University, Egypt 


\section{INTRODUCTION}

The mandible is a unique structure in maxillofacial reconstructive surgery. It has a pivot role in function and aesthetic. Mandible plays a crucial role in mastication, deglutition, phonation, and harmonious lower face appearance ${ }^{(1-3)}$. Mandibular defects impairs function and aesthetics, moreover it disrupt patient's life quality, and social inclusion. Several causes can produce mandibular defects; among them are neoplasms, osteomyelitis, osteoradionecrosis, bisphosphonate-related necrosis, and trauma. Unfortunately, mandibular continuity resection is often unavoidable in many cases ${ }^{(4-6)}$.

Segmental mandibular defects can be generally categorized according to their location and extent. Various classification systems have used to classify this defect ${ }^{(7)}$. The first classification was introduced by Pavlov et al in $1974{ }^{(8)}$. In 1989 , Jewer et al (9) introduced the HCL classification systems; "C" for central defects including both canines, "L" for lateral defects without condylar involvement, " $\mathrm{H}$ " for lateral defects with condylar involvement. In this classification, eight permutations of the 3 letters (C, L, H, LC, HC, LCL, HCL, HH) are used to describe the mandibular defects ${ }^{(7,9,10)}$. Since then, different classifications systems have been proposed as a new systems or modifications for Jewer system (11-14). Jewer classification is still the most widely used classification. Yet, the lack of distinction between small lateral segmental defects, and large lateral segmental defects extended to the ramus or subcondylar region represents a main limitation of Jewer classification ${ }^{(8)}$

Reconstruction of lateral segmental mandibular defects represents a complex clinical challenge for reconstructive surgeons. Various techniques have been used throughout the years. They generally differ in graft type, reconstruction time, and fixation method (1, 7, 10, 15-17). The selection of the optimal technique for lateral segmental mandibular defects has been widely debated. It depends on various local, systemic, social, and economic factors ${ }^{(18-20)}$. The selection of ideal time for reconstruction, either immediate or delayed is controversy. Traditionally, reconstruction is performed in 2 stages. Resection and reconstruction is performed in the first surgery, and after an observation period, the grafting procedure is performed. However with the progressive use of microvascular techniques, it is widely accepted that immediate reconstruction is a reliable alternative for delayed reconstruction ${ }^{(1,5,21-23)}$.

Titanium reconstruction plates are the most commonly used alloplastic devices for both delayed and immediate mandibular reconstruction. They are used to bridge the resection gap, control resection segments, restore continuity, function, and aesthetics (7, 24-26). Proper plate adaptation to the mandibular surface is crucial for the procedure success. Traditionally, the reconstruction plate is bent during the surgery, initially fixed to the mandibular segments, then plate is removed and the mandible is resected, finally the plate is repositioned to the mandibular segments ${ }^{(2)}$. Intraoperative bending of reconstruction plates by trial and is a difficult and time consuming method, leading to longer operation time, higher cost and plate weakening (27). With the introduction of computer-aided surgery and rapid prototyping, preoperative plate bending using 3D mandibular models represents an easier method ${ }^{(27,28)}$.

In both intraoperative (direct) or preoperative (model) method, the reconstruction plate is bent according to the existing mandibular contour before resection. These methods are applicable in cases with no or mild contour deformity ${ }^{(2)}$. Unfortunately, acquired lateral segmental defects usually occurred with pathological neoplasms, associated with contour deformity ${ }^{(7)}$. Various methods have been introduced to encounter these situations; however they are usually time consuming and complicated ${ }^{(2,29-34)}$. In this study, we introduce and assess a new computer guided algorithm using locating holes and 
cutting guides, for mandibular segmental resection in cases with massive contour deformity.

\section{PATIENTS AND METHODS}

This was a prospective study conducted on 6 consecutive cases with mandibular odontogenic neoplasms indicating lateral segmental mandibular resection. The study was conducted from January 2017 till December 2018. Patients were selected according to the following criteria: Patients with large benign odontogenic lesions indicating lateral segmental mandibular resection without condylar involvement (L-Jewer classification); Lesions causing facial asymmetry and mandibular deformity; free from any systematic disease contraindicating the surgical procedures or interfere with normal healing.

\section{Preoperative preparation}

\section{Virtual planning}

Computed tomography (CT) was performed for the mandible using a multi-slice helical CT machine (I-CAT®PreciseTMfrom I-CAT®Technology, Hatfield, PA), with1 mm slice thickness image acquisition, $0.625 \mathrm{~mm}$ slice increment, $0.3 \mathrm{~mm}$ voxel size, 17 X $23 \mathrm{~cm}$ extended field of view, $120 \mathrm{KV}, 5$ $\mathrm{mA}$ and $4 \mathrm{~m}$ exposure time (figure 1 ).

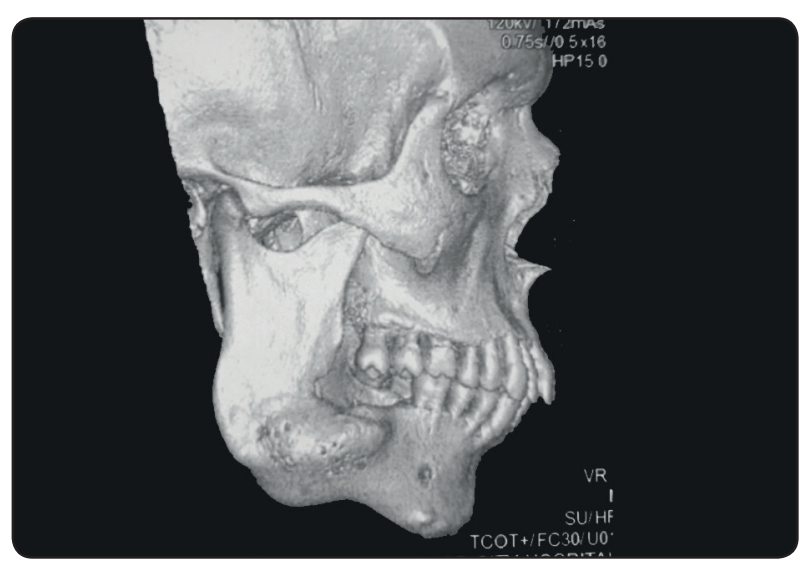

Fig. (1) CT showing mandibular deformity caused by the lesion

CT DICOM (digital Imaging and Communication in Medicine) files were imported to the planning software (Mimics 10.0, Materialise NV, Leuven, Belgium). Mandible was virtually segmented and separated using the software through a series of segmentation and simulation processes. 3D Virtual cutting guide was constructed over the mandibular surface to be resected. To generate a virtual mandibular model with normal contour, mirror imaging of the normal side was performed through facial midline. Two locating holes guides (without holes) were virtually constructed over the surface of the planed distal and proximal segments of the mandible.

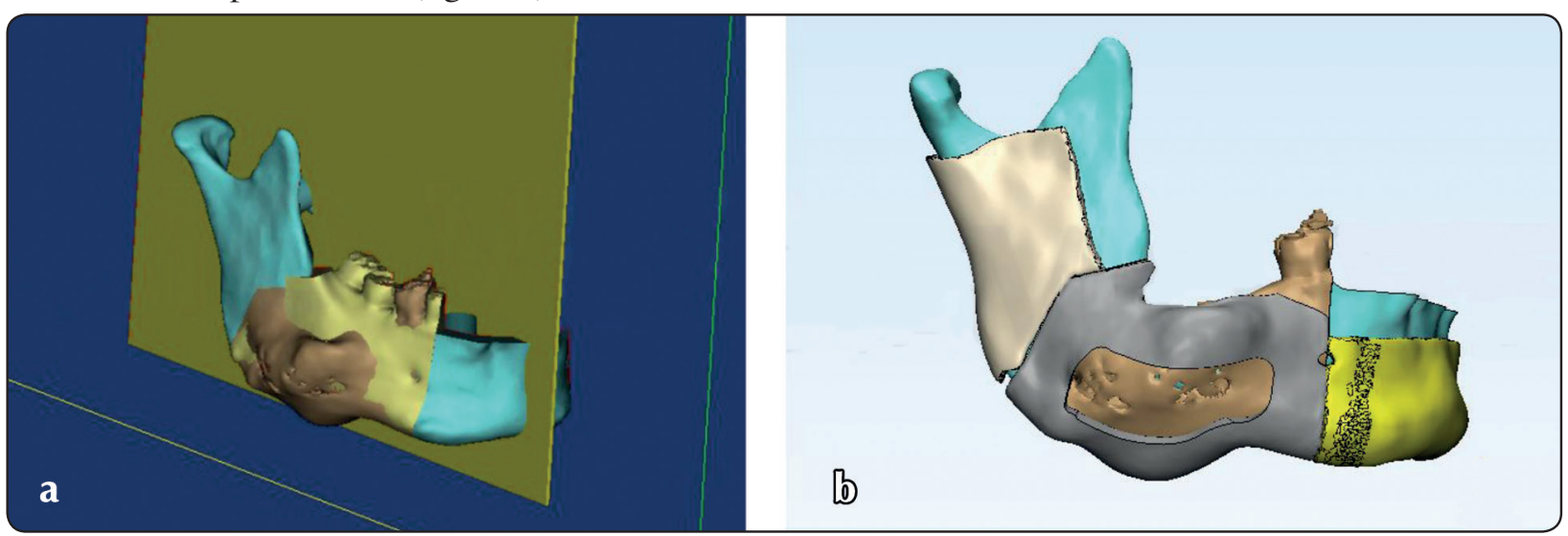

Fig. (2) Virtual planning using the software. a) Planned mandibular contour (blue, yellow) after mirroring of the normal side using facial midline, superimposed over the affected side (brown). b. Locating holes guides (yellow, white), and cutting guide (grey) virtually constructed on the mandible 


\section{Rapid prototyping}

Stereolithographic (STL) files of mandibular model, cutting guide, and the 2 transfer guides were exported to multi-jet modelling printing machine (InVision Si2, 3D Systems e Rock Hill, SC), and fabricated using plastic material (VisiJet SR 200, 3D Systems e Rock Hill, SC).

\section{Reconstruction plate and transfer guides preparation}

Preoperatively, reconstruction plate was bent on the mandibular model (figure 3). After bending, the plate was fixed on the mandiblar model with screws, drilling was performed through the screw holes in the planed position till model lingual surface, finally the plate was removed. Locating holes guides were then prepared to transfer the planned holes positions to the mandible during surgical procedures. Guides were placed over the model in the proposed segments position. Reverse drilling from the lingual surface, and through the previously drilled holes, was performed to perform guide holes in the transfer guide. This step was performed for both proximal and distal transfer guide. Each guide should have at least at least 4 holes (figure 3 ).

\section{Surgical procedures}

Surgical procedures were performed under general anesthesia using nasotracheal intubation.
Submandibular incision was performed to access the lesion, and the posterior part of the mandible, while the mandibular anterior part was accessed through intraoral vestibular incision. The cutting guide was attached to the mandible in the planned position by screws. The distal segment holes transfer guide was placed on the planed mandibular surface, drilling was performed through the holes, after holes localization the screws and the guide were removed. The same procedure was repeated for the proximal segment guide. The segmental resection was then performed. Finally, the reconstruction plate was fixed in the planed position guided by the proximal and distal segments drilled holes, and incisions were sutured (figure 4).

\section{Follow up and Outcomes}

Postoperative CT was performed for all the patients to assess proper positioning of the plate. All patients were followed up for 6 months, and different subjective and objective outcomes were assessed. Recurrence, appearance, occlusion, maximum incisal opening (MIO), chewing, swallowing, speech, pain, and other complications were recorded. For the subjective outcomes (pain, appearance, swallowing, chewing, speech), patients were asked 1 month postoperatively about the outcomes, and a score was recorded

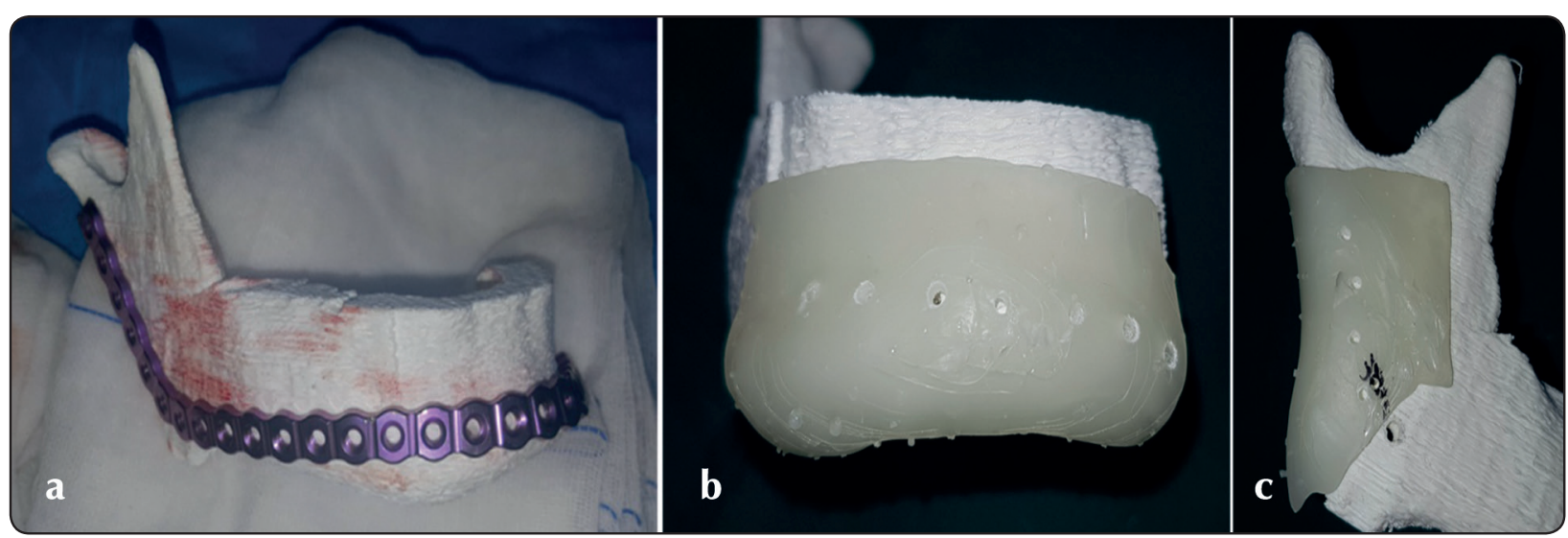

Fig. (3) Preoperative preparations. a. Reconstruction plate probably adapted on mandibular model. b. Distal segment holes transfer guide. c. Proximal segment holes transfer guide. 


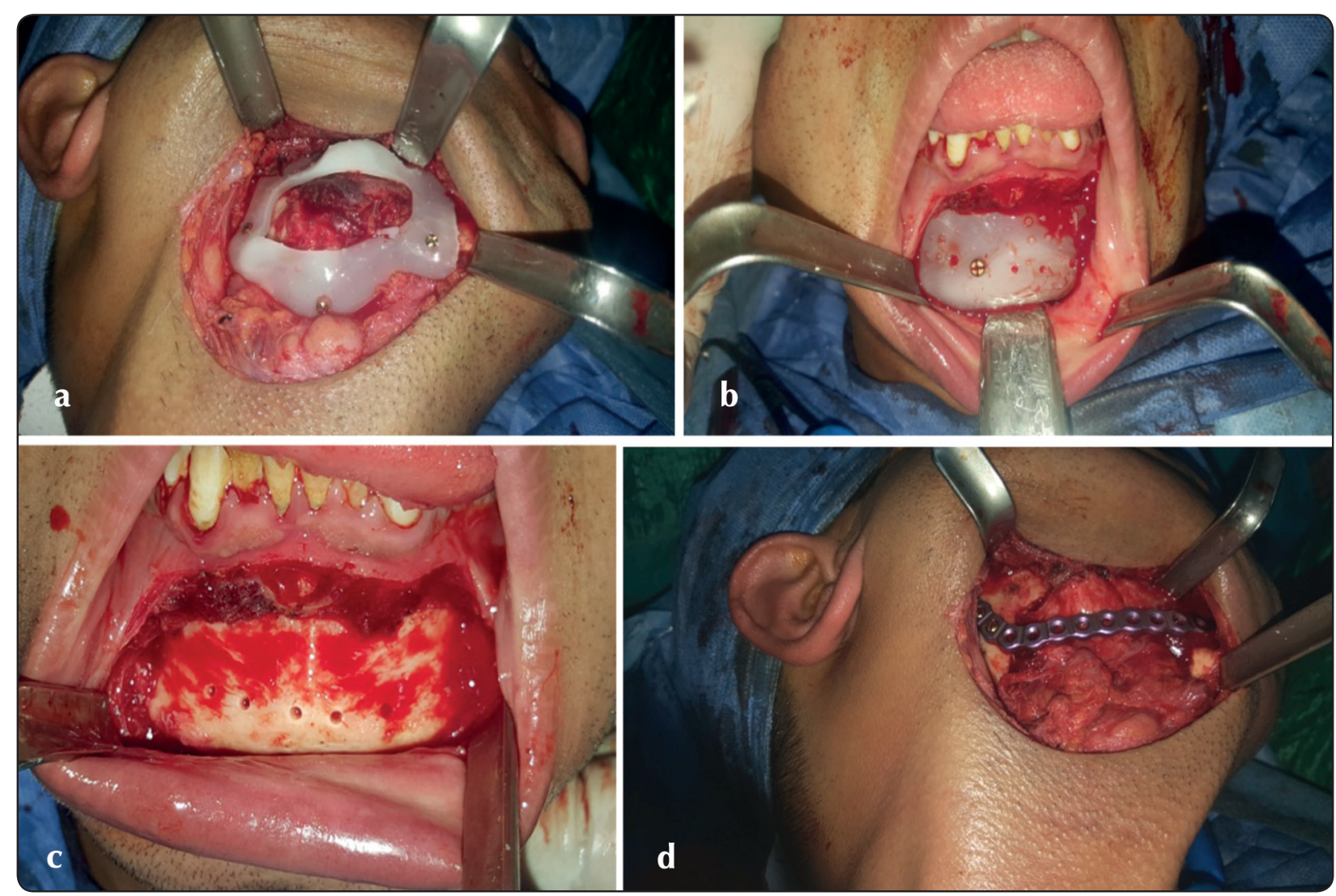

Fig. (4) Surgical procedures. a. Cutting guide fixed in position. b. distal segment locating holes guide fixed to the mandible c. Guiding holes after guide removal. $d$. The reconstruction plate fixed in the planed position after resection.

for each patient. The questions and scores were tailored from University of Washington-Quality of Life Questionnaire (UW-QOL v4) (table 1). Recurrence was evaluated throughout the follow up period. Occlusion was evaluated clinically immediately postoperatively as binary outcome, normal occlusion or mild discrepancy corrected by grinding was considered as success, while severe discrepancy was considered as failure. Maximum incisal opening was measured after 1 and 6 months in millimeters $(\mathrm{mm})$, and any deviation during opening was reported. Other complications (as plate fracture, plate exposure, screw looseness, and

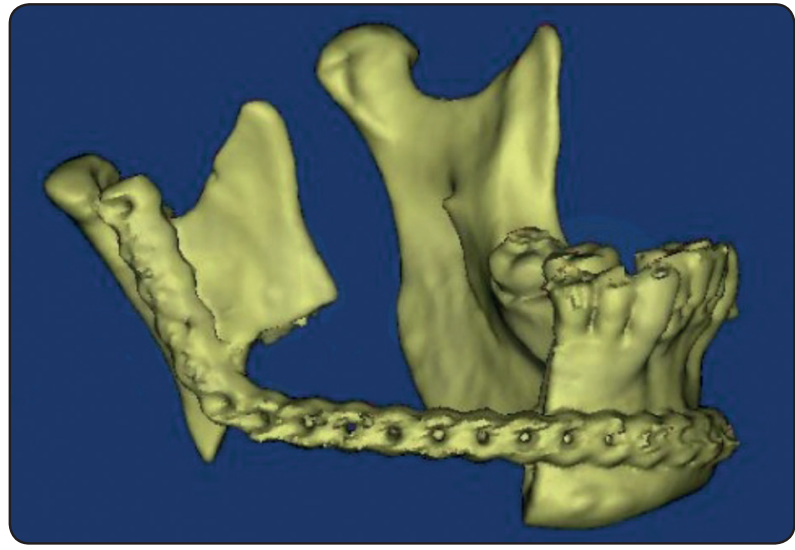

Fig. (5) Postoperative CT showing the reconstruction plate in proper position according to the preoperative plan infection) were recorded (if occurred). 
TABLE (1) Showing different scores for the subjective outcomes.

\begin{tabular}{|c|c|c|}
\hline Outcome & Answer & Score \\
\hline \multirow{5}{*}{ Pain } & No pain & 100 \\
\hline & Mild pain not needing medication. & 75 \\
\hline & $\begin{array}{l}\text { Moderate pain, requires regular } \\
\text { medication. }\end{array}$ & 50 \\
\hline & $\begin{array}{l}\text { Severe pain controlled only by } \\
\text { prescription medicine. }\end{array}$ & 25 \\
\hline & $\begin{array}{l}\text { Severe pain, not controlled by } \\
\text { medication. }\end{array}$ & 0 \\
\hline \multirow{5}{*}{ Appearance } & No change in appearance. & 100 \\
\hline & Minor change in appearance. & 75 \\
\hline & $\begin{array}{l}\text { Bothering appearance; normal } \\
\text { activity. }\end{array}$ & 50 \\
\hline & $\begin{array}{l}\text { Significant disfigurement; limited } \\
\text { activity due to appearance. }\end{array}$ & 25 \\
\hline & No activity due to appearance. & 0 \\
\hline \multirow{4}{*}{ Swallowing } & Swallow as well as ever. & 100 \\
\hline & Can't swallow certain solid foods. & 70 \\
\hline & Can only swallow liquid food. & 30 \\
\hline & Can't swallow. & 0 \\
\hline \multirow{3}{*}{ Chewing } & Chew as well as ever. & 100 \\
\hline & $\begin{array}{l}\text { Eat soft solids but cannot chew } \\
\text { some foods. }\end{array}$ & 50 \\
\hline & Can't even chew soft solids. & 0 \\
\hline \multirow{4}{*}{ Speech } & Speech is the same as always. & 100 \\
\hline & $\begin{array}{l}\text { Difficulty saying some words; can } \\
\text { be understood. }\end{array}$ & 70 \\
\hline & $\begin{array}{l}\text { Only understood by family and } \\
\text { friends. }\end{array}$ & 30 \\
\hline & Can't be understood. & 0 \\
\hline
\end{tabular}

\section{Statistical methods}

Statistical analysis was performed using SPSS (Statistical package for the social sciences- IBM® SPSS ${ }^{\circledR}$ Statistics Version 20 for Windows, IBM Corp., Armonk, NY, USA). Quantitative data were represented as mean \pm standard deviation, explored for normality using Kolmogorov-Smirnov and Shapiro-Wilk tests. For parametric data, Student's t-test was used to compare variables at different time points. While for non-parametric data, Mann-Whitney U test was used. Qualitative data were represented as percentage. The results were considered statistically significant if the $\mathrm{p}$ value was less than 0.05 .

\section{RESULTS}

This study was conducted on 6 patients (4 males, 2 females) with mean age of $35 \pm 7.6$ years. The most common pathological lesion was ameloblastoma (4 cases), followed by desmoplastic fibroma (1 case), and odontogenic keratocyst (1 case). No recurrence occurred in the study till the end of follow up period. $33.3 \%$ of the patients ( 2 patients) observed minor change in appearance, while the rest $(66.7 \%, 4$ patient) observed no change in appearance. 5 patients $(83.3 \%)$ showed normal postoperative occlusion, 1 patient (16.7\%) showed mild discrepancy in occlusion, it was corrected by grinding. The mean MIO was $41.8 \pm 4.35 \mathrm{~mm}$ after 1 month, $42.3 \pm 3.98$ $\mathrm{mm}$ after 6 months, and there was no statistically significant difference between the two time points. Chewing, swallowing, and speech were as normal for 5 patients $(83.3 \%)$, and only patient (16.7 $\%$ ) reported that she cannot chew, and swallow certain solid foods, with some difficulty in saying some words. After 1 month, no pain was reported in the patients. Other possible complications (as plate fracture, plate exposure, screw looseness, and infection) were not encountered in any patient till the end of our 6 months follow up period (table 2). 
TABLE (2) Showing number of patients with different scores for the subjective outcomes.

\begin{tabular}{|c|c|c|c|c|c|c|c|}
\hline & $\mathbf{0}$ & $\mathbf{2 5}$ & $\mathbf{3 0}$ & $\mathbf{5 0}$ & $\mathbf{7 0}$ & $\mathbf{7 5}$ & $\mathbf{1 0 0}$ \\
\hline Pain & 0 & 0 & & 0 & & 0 & 6 \\
\hline Appearance & 0 & 0 & & 0 & & 2 & 4 \\
\hline Swallowing & 0 & & 0 & & 1 & & 5 \\
\hline Chewing & 0 & & & 1 & & & 5 \\
\hline Speech & 0 & & 0 & & 1 & & 5 \\
\hline
\end{tabular}

\section{DISCUSSION}

Segmental mandibular defects reconstruction represents a true challenge for reconstructive surgeons. Mandibular continuity disruption impairs both function and esthetics. Reconstruction aims to restore continuity, contour, aesthetic, and function ${ }^{(4,5,35)}$. Various techniques and protocols have developed for segmental mandibular resection and reconstruction. Regardless the used technique, the first step is to control the resection segments, preserving the positional and angular relation between the proximal and distal segments, and between both segments and the maxilla ${ }^{(1,7,16,17)}$. This step is traditionally accomplished by intermaxillary fixation, and probably adapted reconstruction plate (either intraoperative or preoperative using a printed mandibular model). However, this technique has a major limitation. It is inapplicable in cases with contour deformity. Moreover, the presence of non-dentate proximal segment or/and edentulous distal segment complicates the procedure ${ }^{(2,7,24)}$. We introduce in this study a new computer guided algorithm for mandibular segmental resection without the need of intermaxillary fixation.

The most commonly used method for computer guided preoperative planning is the "model simulation surgery". In this method, preoperative CT was used to construct prototyped models, which simply represents the preoperative condition. Then the surgical procedures are performed on the printed models. Yet, this method is time consuming and inapplicable in numerous cases ${ }^{(29,36)}$. However, with the significant advancement in the virtual planning, various corrections can be performed using the planning software cutting and mirroring tools ${ }^{(37)}$. In this study, we used computer guided planning to: (1) construct cutting guide; (2) reconstruct the deformed side for proper plate adaptation; (3) construct locating holes guides.

Cutting guides have been widely used in mandibular reconstruction surgery. They are used to achieve resection at the preoperatively planned location. Any discrepancy between the planned and actual resection can result in a nonfunctioning reconstruction and affect the radicality of the tumor resection. Cutting guides plays a crucial role to define the surgical margin, assure cutting in normal bone, preventing possible recurrence. In this study, cutting guides showed promising results with no recurrence in all patients. This result is correlated with that reported in other studies ${ }^{(38-40)}$.

The second phase of our virtual planning aims to proper preoperative bending of the reconstruction plate. This was achieved through mirroring of the normal side to create a virtual model, which was printed to $3 \mathrm{D}$ model for preoperative plate bending. Mirror imaging has been successfully used for mandibular reconstruction by different authors ${ }^{(37,41-43)}$. Sieira Gil et al ${ }^{(41)}$, Cohen et al ${ }^{(42)}$, and Lee et al ${ }^{(43)}$ mirror the entire unaffected side to reconstruct a 3D model or plate bending. To the contrary, Khalifa et al ${ }^{(37)}$ recommended the use of segmental mirroring over entire side mirroring. The third phase of our virtual planning was the most critical step. It was performed using the locating holes guide. This step aims to accurately transfer the planned plate position from the model (during preoperative planning) to the mandible (during surgical procedures), using the screw holes as reference points. Lately, Davies et al ${ }^{(44)}$ pointed that segmental mirroring is less accurate where 
pathology involves the mandibular condyle and, to a lesser degree, the coronoid process ${ }^{(44)}$.

Reestablishing mandibular continuity is not the only goal of mandibular reconstruction. Restoring function as mastication, deglutition, speech, and aesthetics are also crucial ${ }^{(3)}$. Our computer guided technique showed promising results regarding quality of life (aesthetic and function) compared to Okoturo et al study ${ }^{(45)}$ using traditional method. In our study, $66.7 \%$ of the patients reported no appearance change, and $33.3 \%$ reported minor change. To the contrary, in Okoturo et al study ${ }^{(45)} 47$ $\%$ of the patients reported bothering appearance, 39 $\%$ reported minor change in appearance. Okoturo study showed $69 \%$ of patients cannot chew some foods and $54 \%$ with difficulty in saying some words, compared to $16.7 \%$ in our study.

The computer guided resection and titanium plate reconstruction using locating holes and cutting guides was found to be beneficial with promising results regarding function and aesthetics. However, the primary limitations of this study were the small sample size, absence of comparator group, and relatively short follow up period. Based on our study, we recommend the use of this technique for initial resection and reconstruction in delayed grafting. Yet, its use as a definitive reconstruction should be subjected to longer follow up period studies.

\section{REFERENCES}

1. Torroni A, Marianetti TM, Romandini M, Gasparini G, Cervelli D, Pelo S. Mandibular reconstruction with different techniques. J Craniofac Surg. 2015 May;26(3):885-90.

2. Wilde F, Winter K, Kletsch K, Lorenz K, Schramm A. Mandible reconstruction using patient-specific pre-bent reconstruction plates: comparison of standard and transfer key methods. Int J Comput Assist Radiol Surg. 2015 Feb;10(2):129-40.

3. Pirgousis P, Eberle N, Fernandes R. Reoperative mandibular reconstruction. Oral Maxillofac Surg Clin North Am. $2011 \mathrm{Feb}$;23(1):153-60.
4. Moura LB, Carvalho PH, Xavier CB, Post LK, Torriani MA, Santagata M, Chagas Júnior OL. Autogenous nonvascularized bone graft in segmental mandibular reconstruction: a systematic review. Int J Oral Maxillofac Surg. 2016 Nov;45(11):1388-1394.

5. Hussein KA, Zakhary IE, Hailat D, Elrefai R, Sharawy M, Elsalanty ME. Delayed versus immediate reconstruction of mandibular segmental defects using recombinant human bone morphogenetic protein 2/absorbable collagen sponge. J Oral Maxillofac Surg. 2013 Jun;71(6):1107-18.

6. Hayden RE1, Mullin DP, Patel AK. Reconstruction of the segmental mandibular defect: current state of the art. Curr Opin Otolaryngol Head Neck Surg. 2012 Aug; 20(4):231-6.

7. Kumar BP, Venkatesh V, Kumar KA, Yadav BY, Mohan SR. Mandibular Reconstruction: Overview. J Maxillofac Oral Surg. 2016 Dec;15(4):425-441.

8. Brown JS, Barry C, Ho M, Shaw R. A new classification for mandibular defects after oncological resection. Lancet Oncol. 2016 Jan;17(1):e23-30.

9. Jewer DD, Boyd JB, Manktelow RT, Zuker RM, Rosen IB, Gullane PJ, Rotstein LE, Freeman JE. Orofacial and mandibular reconstruction with the iliac crest free flap: a review of 60 cases and a new method of classification. Plast Reconstr Surg. 1989 Sep;84(3):391-403.

10. Chim H, Salgado CJ, Mardini S, Chen HC. Reconstruction of mandibular defects. Semin Plast Surg. 2010 May;24(2):188-97.

11. Urken ML, Weinberg H, Vickery C, Buchbinder D, Lawson W, Biller HF. Oromandibular reconstruction using microvascular composite free flaps. Report of 71 cases and a new classification scheme for bony, soft-tissue, and neurologic defects. Arch Otolaryngol Head Neck Surg. 1991 Jul;117(7):733-44.

12. Iizuka T, Häfliger J, Seto I, Rahal A, Mericske-Stern R, Smolka K. Oral rehabilitation after mandibular reconstruction using an osteocutaneous fibula free flap with endosseous implants. Factors affecting the functional outcome in patients with oral cancer. Clin Oral Implants Res. 2005 Feb;16(1):69-79.

13. Baumann DP, Yu P, Hanasono MM, Skoracki RJ. Free flap reconstruction of osteoradionecrosis of the mandible: a 10-year review and defect classification. Head Neck. 2011 Jun;33(6):800-7. 
14. Hashikawa K, Yokoo S, Tahara S. Novel classification system for oncological mandibular defect: CAT classification. Jpn J Head Neck Cancer. 2008;34:412-418.

15. Pogrel MA, Schmidt BL. Mandibular Reconstruction. In: Andersson L, Kahnberg KE, Pogrel MA. Oral and maxillofacial surgery. Blackwell Publishing Ltd; 2010. P 1009-123.

16. Goh BT, Lee S, Tideman H, Stoelinga PJ. Mandibular reconstruction in adults: a review. Int J Oral Maxillofac Surg. 2008 Jul;37(7):597-605.

17. Foster RD, Anthony JP, Sharma A, Pogrel MA. Vascularized bone flaps versus nonvascularized bone grafts for mandibular reconstruction: an outcome analysis of primary bony union and endosseous implant success. Head Neck. 1999 Jan;21(1):66-71.

18. August M, Tompach P, Chang Y, Kaban L. Factors influencing the long-term outcome of mandibular reconstruction. J Oral Maxillofac Surg. 2000 Jul;58(7):731-7.

19. Kämmerer PW, Klein MO, Moergel M, Gemmel M, Draenert GF. Local and systemic risk factors influencing the long-term success of angular stable alloplastic reconstruction plates of the mandible. J Craniomaxillofac Surg. 2014 Jul;42(5):e271-6.

20. Young CW, Pogrel MA, Schmidt BL. Quality of life in patients undergoing segmental mandibular resection and staged reconstruction with nonvascularized bone grafts. J Oral Maxillofac Surg. 2007 Apr;65(4):706-12.

21. Lonie S, Herle P, Paddle A, Pradhan N, Birch T, Shayan R. Mandibular reconstruction: meta-analysis of iliac- versus fibula-free flaps. ANZ J Surg. 2016 May;86(5):337-42.

22. Vu DD, Schmidt BL. Quality of life evaluation for patients receiving vascularized versus nonvascularized bone graft reconstruction of segmental mandibular defects. J Oral Maxillofac Surg. 2008 Sep;66(9):1856-63.

23. Schlieve T, Hull W, Miloro M, Kolokythas A. Is immediate reconstruction of the mandible with nonvascularized bone graft following resection of benign pathology a viable treatment option? J Oral Maxillofac Surg. 2015 Mar;73(3):541-9.

24. Gutwald R, Jaeger R, Lambers FM. Customized mandibular reconstruction plates improve mechanical performance in a mandibular reconstruction model. Comput Methods Biomech Biomed Engin. 2017 Mar;20(4):426-435.

25. Ferreira JJ, Zagalo CM, Oliveira ML, Correia AM, Reis AR. Mandible reconstruction: History, state of the art and persistent problems. Prosthet Orthot Int. 2015 Jun;39(3):182-9.

26. Goh BT, Lee S, Tideman H, Stoelinga PJ. Mandibular reconstruction in adults: a review. Int J Oral Maxillofac Surg. 2008 Jul;37(7):597-605.

27. Velasco I, Vahdani S, Ramos H. Low-cost Method for Obtaining Medical Rapid Prototyping Using Desktop 3D printing: A Novel Technique for Mandibular Reconstruction Planning. J Clin Exp Dent. 2017 Sep 1;9(9):e1103e1108.

28. Ahmed M, Ali S. Computer guided temporomandibular joint reconstruction of Kaban III hemifacial microsomia with anotia: A case report. Int J Surg Case Rep. 2019 Mar $16 ; 57: 52-56$

29. Hallermann W, Olsen S, Bardyn T, Taghizadeh F, Banic A, lizuka T. A new method for computer-aided operation planning for extensive mandibular reconstruction. Plast Reconstr Surg. 2006 Jun;117(7):2431-7.

30. Cornelius CP, Augustin JB, Sailer LK. External pin fixation for stabilization of the mandible--comeback of a method: historical review and first experiences with the 'mandible external fixator'. Oral Maxillofac Surg. 2009 Mar;13(1):1-14.

31. Reece GP, Martin JW, Lemon JC, Jacob RF. Mandible fragment fixation during reconstruction: the splint-andplate technique. Ann Plast Surg. 1993 Aug;31(2):128-33.

32. Mohindra A, Blanco-Guzman MM. Temporary mandibular stabilisation during reconstruction: an alternative technique. Br J Oral Maxillofac Surg. 2009 Jul;47(5):399-400.

33. Iwai S1, Moriyama T, Amekawa S, Katagiri W, Nakazawa M, Yura Y. A modified repositioning system for segmental resection of the mandible. Int J Oral Maxillofac Surg. 2006 Mar; 35(3):270-3

34. Tominaga K, Yoshioka I, Khanal A, Furuta N, Habu M, Fukuda J. A simple method for bone positioning of mandibular segments. Int J Oral Maxillofac Surg. 2006 Sep;35(9):856-60.

35. Rana M, Warraich R, Kokemüller H, Lemound J, Essig H, Tavassol F, Eckardt A, Gellrich NC. Reconstruction of mandibular defects - clinical retrospective research over a 10-year period -. Head Neck Oncol. 2011 Apr 28;3:23.

36. Kernan BT, Wimsatt JA 3rd. Use of a stereolithography model for accurate, preoperative adaptation of a reconstruction plate. J Oral Maxillofac Surg. 2000 Mar;58(3):349-51. 
37. Khalifa GA, Abd El Moniem NA, Elsayed SA, Qadry Y. Segmental Mirroring: Does It Eliminate the Need for Intraoperative Readjustment of the Virtually Pre-Bent Reconstruction Plates and Is It Economically Valuable? J Oral Maxillofac Surg. 2016 Mar;74(3):621-30.

38. Tarsitano A, Del Corso G, Ciocca L, Scotti R, Marchetti C. Mandibular reconstructions using computer-aided design/ computer-aided manufacturing: A systematic review of a defect-based reconstructive algorithm. J Craniomaxillofac Surg. 2015 Nov;43(9):1785-91.

39. Weitz J, Wolff KD, Kesting MR, Nobis CP. Development of a novel resection and cutting guide for mandibular reconstruction using free fibula flap. J Craniomaxillofac Surg. 2018 Nov;46(11):1975-1978.

40. Weijs WL, Coppen C, Schreurs R, Vreeken RD, Verhulst AC, Merkx MA, Bergé SJ, Maal TJ. Accuracy of virtually 3D planned resection templates in mandibular reconstruction. J Craniomaxillofac Surg. 2016 Nov;44(11):1828-1832.

41. Sieira Gil R, Roig AM, Obispo CA, Morla A, Pagès CM, Perez JL. Surgical planning and microvascular reconstruc- tion of the mandible with a fibular flap using computeraided design, rapid prototype modelling, and precontoured titanium reconstruction plates: a prospective study. $\mathrm{Br} \mathrm{J}$ Oral Maxillofac Surg. 2015 Jan;53(1):49-53.

42. Cohen A, Laviv A, Berman P, Nashef R, Abu-Tair J. Mandibular reconstruction using stereolithographic 3-dimensional printing modeling technology. Oral Surg Oral Med Oral Pathol Oral Radiol Endod. 2009 Nov;108(5):661-6.

43. Lee JW, Fang JJ, Chang LR, Yu CK. Mandibular defect reconstruction with the help of mirror imaging coupled with laser stereolithographic modeling technique. J Formos Med Assoc. 2007 Mar; 106(3):244-50.

44. Davies JC, Chan HHL, Jozaghi Y, Goldstein DP, Irish JC. Analysis of simulated mandibular reconstruction using a segmental mirroring technique. J Craniomaxillofac Surg. 2019 Mar;47(3):468-472.

45. Okoturo E, Ogunbanjo O, Akinleye A, Bardi M. Quality of life of patients with segmental mandibular resection and immediate reconstruction with plates. J Oral Maxillofac Surg. 2011 Aug;69(8):2253-9. 